\title{
PRÁTICAS NO LAZER DE REFUGIADOS RESIDENTES EM FLORIANÓPOLIS-SC
}

Recebido em: 12/08/2020

Aprovado em: 08/05/2021

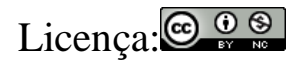

Rubian Diego Andrade 1

Caio Hercilio Martins ${ }^{2}$

Instituto de Ensino Superior da Grande Florianópolis (IESGF)

São José - SC - Brasil

RESUMO: O presente estudo teve por objetivo identificar a diferença entre o envolvimento nas práticas de lazer exercido por refugiados residentes em FlorianópolisSC, com relação ao seu país de origem. Utilizou-se o instrumento Escalas de Práticas no Lazer (EPL) para identificar o a realização das práticas nos diferentes contextos do lazer. A diferença estatística entre os dois momentos $(\mathrm{p}=0,002)$ indicou que $\mathrm{o}$ envolvimento em práticas no lazer foi menor no contexto atual $(36,44(17,1)$ pontos) quando comparada ao contexto de origem $(46,00(20,8)$ pontos $)$, especialmente nos conteúdos artístico $(\mathrm{p}<0,001)$, físico-esportivo $(\mathrm{p}=0,024)$ e turístico $(\mathrm{p}<0,001)$ do lazer.Verificou-se também que houve diminuição em todos os domínios do lazer, indicando que esta população necessita de um olhar das políticas públicas visto que as práticas no lazer contribuem para o desenvolvimento pessoal, social, para qualidade de vida e dignidade humana.

PALAVRAS-CHAVE: Atividades de Lazer. Refugiados. Qualidade de Vida.

\section{PRACTICES IN THE LEISURE OF RESIDENTS IN FLORIANOPOLIS-SC}

ABSTRACT: The present study aimed toidentify the difference between the involvement in leisure practices carried out by refugees residing in Florianopolis-SC, in relation to their country of origin. The instrument Practical Scales in Leisure (EPL) was used to identify the performance of the practices in the different leisure contexts. The statistical difference between the two moments $(\mathrm{p}=0.002)$ indicated that the involvement in leisure practices was lower in the current context (36.44 (17.1) points) when compared to the context of origin (46.00 (20.8) points, especially in the artistic ( $p$ $<0.001)$, physical-sports $(\mathrm{p}=0.024)$ and tourism $(\mathrm{p}<0.001)$ contents of leisure. It was also observed that there was a decrease in all domains of leisure, indicating that this population needs a look at public policies since leisure practices contribute to personal, social, quality of life development and human dignity.

KEYWORDS: Leisure Activities. Refugees. Quality of Life.

\footnotetext{
${ }^{1}$ Docente do curso de Educação Física do Instituto de Ensino Superior da Grande Florianópolis (IESGF).

2 Acadêmico do curso de Educação Física do Instituto de Ensino Superior da Grande Florianópolis (IESGF).
} 


\section{Introdução}

O mundo está vivenciando um quadro preocupante nos últimos anos, no qual a situação dos refugiados vem se agravando de forma continuada. Perseguidos por motivos políticos, étnicos ou de crença religiosa esta população não encontra outra maneira de sobreviver, a não ser, sendo obrigada a fugir para outros países, na incessante busca por abrigo, trabalho e dignidade humana.

Segundo Kaplan e Chacko (2015) o local onde o imigrante viverá é um fator primordial para integração na nova sociedade. Segundo dados divulgados em relatório do CONARE (Comitê Nacional para Refugiados), foram reconhecidos no Brasil até o fim de 2016, 9.552 refugiados de 82 nacionalidades. Desses, 8.552 foram reconhecidos por trâmites tradicionais de elegibilidade, 713 por meio de reassentamento e outros 317 foram via condição de refugiado de algum familiar (CONARE, 2017). Portanto, tal problemática faz emergir novos olhares a esta população que busca no Brasil uma nova perspectiva de vida.

Neste contexto, no ponto de vista de Prilleltensky (2008), o bem-estar individual está diretamente ligado a relações pessoais e da comunidade onde o indivíduo reside. Assim, autores relacionaram a importância da cultura para o desenvolvimento da constituição psíquica e da saúde mentaldo sujeito (FREITAS, 2013; MARTINS, 2013; MORO, 2015; MOUNTIAN; ROSA, 2015). Ao indivíduo que tem a chance de escapar da falta de oportunidades de seu país de origem, o processo de mudança resulta em efeitos positivos no bem-estar dos mesmos (NIKOLOVA; GRAHAM, 2015).No entanto, são comuns na vida de refugiados níveis mais baixos de autoestima e eventos estressantes constantes (SLONIM-NEVO et al., 2006). Apesar disso, há de se considerar que na luta para encontrar oportunidades de trabalho, construir vida social e conjugar sua identidade cultural com uma nova cultura, refugiados separam-se de 
pessoas e lugares onde já estavam habituados (HOVEY; MAGAÑA, 2002), o que pode repercutir em outros aspectos da vida social como o lazer. Nesse sentido, as práticas no lazer configuram-se em uma oportunidade de ressocialização, bem como no desenvolvimento de novas perspectivas de vida.

Acerca da temática, alguns autores, ao longo do tempo vem contribuindo para a entendimento do conceito de lazer no Brasil. Nessa perspectiva, e, considerando o tema abordado serão apresentadas dois deles. Para Camargo (2017), o lazer é representado em um tempo livre ou sob a forma de trabalho profissional e doméstico que se ressignificam e manifestam-se sob ações gratuitas, prazerosas, voluntárias e liberatórias, centradas em interesses culturais, influenciando assim, no desenvolvimento pessoal dos indivíduos. O autor, portanto, enfatiza a importância das práticas no lazer para o processo de construção da identidade e socialização.

Já Gomes (2014), compreende o lazer como uma necessidade humana e dimensão da cultura. A autora completa que as práticas sociais vivenciadas ludicamente pelos sujeitos, estão presentes na vida cotidiana em todos os tempos, lugares e contextos. Assim, entende-se que o envolvimento em práticas no lazer faz-se presente independentemente do contexto inserido, sendo assim, uma característica intrínseca do ser humano vivenciar as práticas no lazer.

No que tange ao universo acadêmico, são escassos o número de estudos abordando a temática do lazer relacionando a população de refugiados. No entanto, sob o prisma social, é latente a relevância da temática. O influxo de pessoas na condição de refugiadas ao abrigo do Brasil traz à tona as disposições jurídicas atinentes a este estudo. Por meio do Decreto n $^{\circ} 50.215 / 1961$, o Brasil promulgou a Convenção relativa ao Estatuto dos Refugiados, concluída em Genebra, em 28 de julho de 1951 (ONU, 1951). Mais tarde, a Lei $n^{\circ} 9.474$, publicada em 1997, definiu os mecanismos formais 
para a implementação do referido Estatuto no país. O Estatuto dos Refugiados, atrelado à Declaração Universal de Direitos Humanos (1948), estabelece, em seu artigo 23, que os refugiados têm os mesmos direitos, em matéria de assistência e socorros públicos, que os próprios nativos (BRASIL, 2018).

Neste ínterim, o Brasil, como subscritor de tratado internacional de direitos humanos, não pode deixar de seguir as diretrizes assumidas. Com base nisso, em relação aos seus direitos fundamentais, inegável que os refugiados brasileiros merecem o tratamento igualitário aos próprios cidadãos brasileiros, e por isso são submetidos aos mesmos deveres e aos mesmos direitos, tal qual o direito social ao lazer (Constituição Federal, artigo $6^{\circ}$ ) (BRASIL, 1988), Razão pela qual o presente estudo assume imponente importância de identificar a diferença entre o envolvimento nas práticas de lazer exercidas por refugiados residentes em Florianópolis-SC, com relação ao seu país de origem. Favorecendo assim, o entendimento das mudanças ocorridas nesse contexto da vida do ser humano em processo de nova identidade territorial, promovendo subsídios para novas políticas públicas de promoção de bem-estar e de lazer para esta população e ações do Estado para a consecução dos objetivos assumidos em âmbito internacional.

\section{Método}

Esse estudo caracteriza-se como uma pesquisa do tipo descritiva de cunho transversal. Foi submetido e aprovado junto ao Comitê de Ética em Pesquisas envolvendo Seres Humanos da Universidade Paulista CEPSH-UNIP (parecer número 2.718.150/2018), seguindo as diretrizes de pesquisa em seres humanos, segundo Resolução 466/12 do Conselho Nacional de Saúde (BRASIL, 2013). 
Os participantes deste estudo foram formados por refugiados residentes em Florianópolis - SC de ambos os sexos que frequentavam aulas do curso de Língua Portuguesa e cultura brasileira para estrangeiros de uma Instituição Federal de Ensino Superior.

Determinaram-se como critérios de inclusão aqueles refugiados que declararem residir na cidade de Florianópolis em um período mínimo de seis meses e maiores de 18 anos. Foram excluídos aqueles que não conseguirem falar e ler na língua portuguesa e ter idade inferior a 18 anos. Para àqueles que conseguiam se comunicar em Português, mas possuíam dificuldade apenas na escrita, a aplicação dos questionários deu-se por meio de entrevista individualizada. Sendo assim, incluídos na pesquisa. Os dados foram coletados em sala de aula, em dias e horários aprovados pela direção da instituição.

Para caracterização da amostra foram coletadas informações sociodemográfica como idade (em anos), tempo em que reside em Florianópolis (em anos), país de origem, nível de escolaridade (fundamental, médio e superior), se possuía emprego (sim ou não), jornada de trabalho (horas semanais), renda pessoal (em reais) e estado civil (com companheiro (a) ou sem companheiro (a)).

Recrutou-se para avaliar a variável dependente do estudo a Escala de Práticas no Lazer (EPL). O instrumento visa identificar o envolvimento em práticas nos diferentes contextos do lazer em adultos, utilizando um questionário a partir dos conteúdos culturais do lazer (artístico, manual, físico-esportivo, intelectual, social, turístico, virtual e contemplação/ócio) (ANDRADE et al., 2018). O instrumento foi validado por Andrade et al. (2018) para população adulta a partir da análise de conteúdo por especialistas em lazer, da reprodutibilidade em teste-reteste e da consistência interna, apresentando bons índices de validade. Além disso, já foi utilizada em algumas para avaliação das práticas no lazer no Brasil em diferentes contextos (ANDRADE et al., 
2017; ANDRADE; SCHWARTZ; FELDEN, 2018; MEIRA; ANDRADE, 2019; BRITO et al., 2019). A escala do tipo Likert, apresenta ao indivíduo mais opções de respostas, respeitando sua percepção individual de muito ou pouco envolvimento em determinado contexto. Para cada conteúdo cultural do lazer a escala vai de "zero"' (envolvimento mínimo no conteúdo cultural do lazer analisado) a "10" (envolvimento máximo no conteúdo cultural do lazer analisado). Para responder ao objetivo da pergunta norteadora da presente pesquisa, solicitou-se aos participantes que respondessem a EPL considerando as duas questões: $1^{\text {a }}$ ) Responda as questões a seguir, levando em consideração a sua vida em seu país de origem; $2^{a}$ ) Responda as seguintes questões levando em consideração a sua vida atual em Florianópolis. Tal estratégia procurou facilitar o entendimento de cada indivíduo dentro dos contextos analisados, a realidade atual e no seu país de origem.

Para análises dos dados foram utilizadas estatística descritiva e inferencial. Nas análises descritivas foram usadas médias e desvios padrões para os dados contínuos e frequência relativa e absoluta para as variáveis categóricas. A distribuição não normal dos dados foi analisada por meio do teste de Shapiro-Wilk. Portanto, para as análises inferenciais recrutou-se o teste de Wilcoxon para identificar a diferença entre a pontuação da EPL nos dois contextos analisados e o teste de Spearman para a correlação entre as variáveis. O programa estatístico utilizado para a análise dos dados foi o software Statistical Package for the Social Sciences (SPSS) for Windows versão 20.0. Para todas as análises, foi considerado um nível de significância de 5\% ( $\mathrm{p}<0,05)$.

\section{Resultados}

Na Tabela 1 foram apresentados os dados descritivos da amostra. Observou-se que a maioria dos participantes era do sexo feminino $(58,1 \%)$, a média de idade entre os 
foi de $31,84(9,4)$ anos. A maior parte declarou ter o ensino superior completo $(53,5 \%)$, possuir trabalho $(55,8 \%)$ com jornada acima das 40 horas semanais, e declarou possuir companheiro(a) $(67,4 \%)$. O tempo em Florianópolis foi de aproximadamente um ano e oito meses.

\section{Tabela 1: Caracterização da amostra}

\begin{tabular}{lrr}
\hline \multicolumn{1}{c}{ Variáveis } & n & Índices \\
\hline Sexo, \% & & \\
$\quad$ Masculino & 18 & 41,9 \\
$\quad$ Feminino & 25 & 58,1 \\
Idade, anos(dp) & 43 & $31,84(9,4)$ \\
Tempo em Florianópolis, meses(dp) & 43 & $20,19(18,2)$ \\
Trabalho, \% & & \\
$\quad$ Sim & 24 & 55,8 \\
$\quad$ Não & 19 & 44,2 \\
Jornada de trabalho, horas/semana(dp) & 24 & $42,9(8,2)$ \\
Escolaridade, \% & & \\
$\quad$ Nível fundamental & 4 & 37,3 \\
$\quad$ Nível médio & 16 & 53,5 \\
$\quad$ Nível superior & 23 & 67,4 \\
Estado civil, \% & & 32,6 \\
$\quad$ Com companheiro(a) & 29 & \\
$\quad$ Sem companheiro(a) & 14 &
\end{tabular}

Na Figura 1 foram apresentados em formato de pictograma a frequência relativa da distribuição do país de origem dos participantes da pesquisa. Destaca-se que a grande maioria é de origem do país da América Central Haiti (65,1\%), seguidos na sequencia pelos países da América do Sul, Venezuela (14\%), Chile (7,0\%), Colômbia (7,0\%), Argentina e Uruguai com 2,3\%, e do país Africano de Togo $(2,3)$. 
Figura 1: Pictograma de distribuição da frequência relativa referente ao país de origem dos participantes da pesquisa.

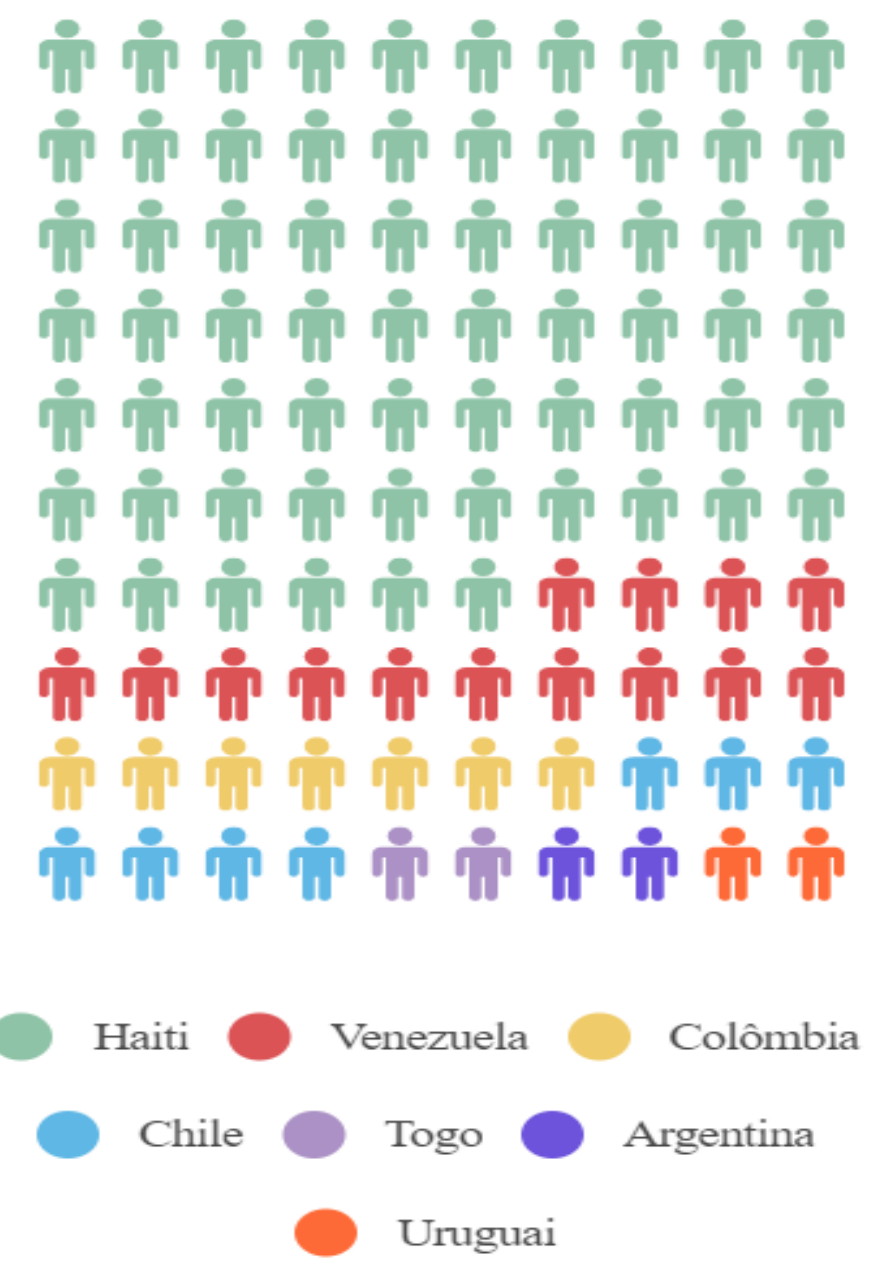

A Figura 2 apresenta a diferença entre a pontuação total da EPL considerando os dois contextos analisados. A diferença estatística $(\mathrm{p}=0,002)$ indica que o envolvimento em práticas no lazer foi menor no contexto atual $(36,44(17,1)$ pontos $)$ quando comparada ao contexto de origem $(46,00(20,8)$ pontos $)$. 


\section{Figura 2: Diferença da pontuação total da EPL de acordo com os contextos analisados}

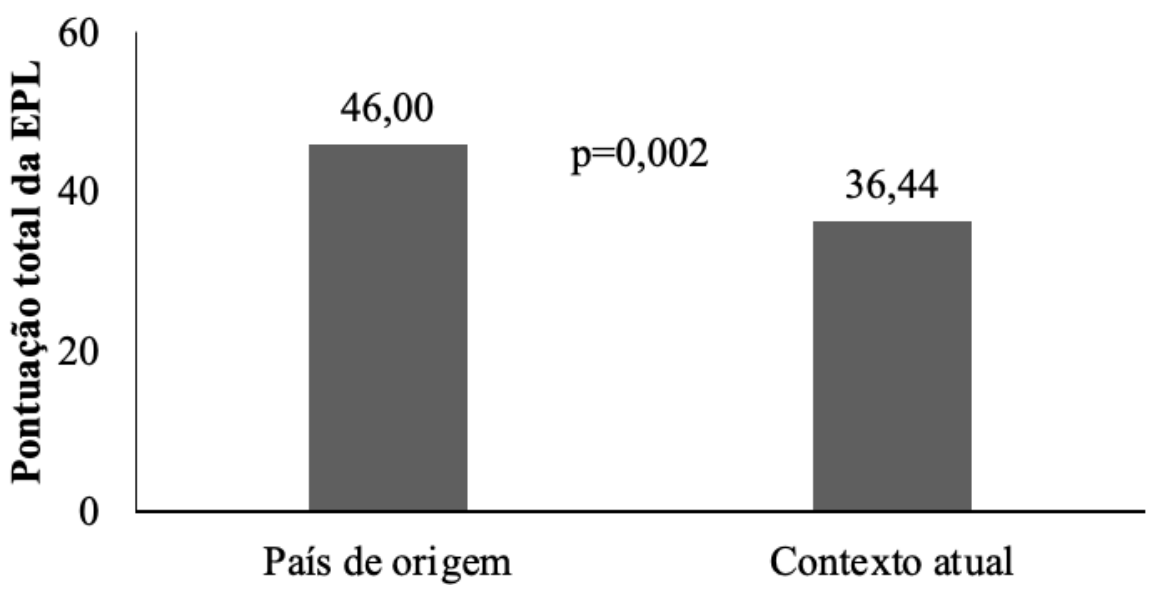

No sentido de aprofundar a análise anterior, na Tabela 2 apresenta-se a diferença da pontuação da EPL considerando os seus domínios. Verificou-se que houve uma diminuição em todos eles considerando o contexto atual em relação ao do país de origem. Porém, as diferenças significativas $(\mathrm{p}<0,05)$ foram identificadas nos conteúdos artísticos (país de origem 6,00(3,4) pontos; e no contexto atual 3,19(3,3) pontos, seguido pelo conteúdo físico-esportivo (país de origem $6,07(3,7)$ pontos; e contexto atual $5,16(3,7)$ pontos), e turístico (país de origem $3,88(3,8)$ pontos; e contexto atual $1,84(2,9)$ pontos).

Tabela 2: Diferença da pontuação dos domínios EPL considerando contextos de vida

\begin{tabular}{lrrr}
\hline Domínios da EPL & País de origem & Contexto atual & p-valor \\
\hline Artístico, X(dp) & $6,00(3,4)$ & $3,19(3,3)$ & $<\mathbf{0 , 0 0 1}$ \\
Manual, X(dp) & $6,86(9,0)$ & $4,86(3,9)$ & 0,072 \\
Físico-esportivo, X(dp) & $6,07(3,7)$ & $5,16(3,7)$ & $\mathbf{0 , 0 2 4}$ \\
Intelectual, X(dp) & $5,14(3,4)$ & $4,91(3,7)$ & 0,622 \\
Social, X(dp) & $7,19(3,0)$ & $6,40(3,5)$ & 0,131 \\
Turístico, X(dp) & $3,88(3,8)$ & $1,84(2,9)$ & $<\mathbf{0 , 0 0 1}$ \\
Virtual, X(dp) & $5,81(3,5)$ & $5,56(3,9)$ & 0,451 \\
Contemplação/ócio, X(dp) & $5,05(3,9)$ & $4,53(3,8)$ & 0,251 \\
\hline
\end{tabular}

$\mathrm{X}=$ média; $\mathrm{dp}=$ desvio padrão; $\mathrm{p}$-valor do teste de Wilcoxon

A Tabela 3 apresenta a correlação entre a pontuação da EPL em seus domínios considerando os dois momentos. Esta análise apresentou índices significativos e 
positivos com correlações de moderadas a forte, indicando que, apesar da diminuição em todos os domínios do lazer (Tabela 2), quanto maior fosse o envolvimento nas práticas no lazer no país de origem, maior também era o envolvimento em atividades no lazer no contexto atual.

Tabela 3: Correlação entre a pontuação dos domínios EPL considerando contextos de vida

\begin{tabular}{lrr}
\hline Domínios da EPL & rho & p-valor \\
\hline Artísticos & 0,324 & $\mathbf{0 , 0 3 4}$ \\
Manual & 0,580 & $<\mathbf{0 , 0 0 1}$ \\
Físico-esportivo & 0,776 & $<\mathbf{0 , 0 0 1}$ \\
Intelectual & 0,432 & $\mathbf{0 , 0 0 4}$ \\
Social & 0,546 & $<\mathbf{0 , 0 0 1}$ \\
Turístico & 0,561 & $<\mathbf{0 , 0 0 1}$ \\
Virtual & 0,751 & $<\mathbf{0 , 0 0 1}$ \\
Contemplação/ócio & 0,701 & $<\mathbf{0 , 0 0 1}$ \\
Pontuação total & 0,540 & $<\mathbf{0 , 0 0 1}$ \\
\hline ro
\end{tabular}

rho = índice de correlação de Spearman; p-valor da correlação de Spearman

\section{Discussão}

Este estudo objetivou identificar a diferença entre o envolvimento nas práticas de lazer exercidas por refugiados residentes em Florianópolis-SC, com relação ao seu país de origem. O principal resultado do trabalho mostrou que, perante a diferença estatística, o envolvimento em práticas no lazer foi menor no contexto atual, quando comparada ao contexto de origem. Em estudo realizado com refugiados Sírios e Iraquianos, Murad e Versey (2020) relaram que menor tempo de lazer resulta em níveis mais baixos de participação social e menos amizades. Os autores apontam por conta das diferenças culturais alguns participantes relatam se sentir mais isolados socialmente e, geralmente, menos apoiados. Assim, segundo as autoras o menor envolvimento em práticas no lazer pode dificultar ou atrasar a formação de relacionamentos e construção do sentimento de pertencer-se a determinada comunidade (MURAD; VERSEY, 2020). Além disso, o sofrimento associado à condição de refúgio pode trazer consequências mais ou menos grave para essa população, ainda que não tenha sido objetivo deste 
estudo, especula-se que dentre os motivos que possam ter contribuído para estes resultados, podem estar níveis baixos de autoestima e maiores números de eventos estressantes, o que é comum na vida dos imigrantes (SLONIM-NEVO et al., 2006).

Ainda que o lazer esteja associado a diferentes dimensões do desenvolvimento da sociedade, sua relação com a saúde também é bastante relatada (GÁSPARI; SCHWARTZ, 2001). Nesse sentido, é importante compreender o fenômeno lazer para além da diversão, das práticas consumistas e do entretenimento. Deve a ele ser atribuído sua função social de direito estabelecido na Constituição Federal e na Declaração dos Direitos Humanos, como a educação, a saúde, o trabalho e moradia (MARCELLINO, 2012). Tendo em vista que as atividades no contexto do lazer favorecem a promoção da saúde, o envolvimento humano em atividades hedonistas com base em afinidades ou competências pessoais, reforçam a perspectiva de desenvolvimento no âmbito pessoal ou social, tendo impacto na saúde e na qualidade de vida dos sujeitos (MARCELLINO, 2012; NAHAS et al., 2010).

A análise das características gerais da amostra apresenta um diagnóstico do perfil dos refugiados que buscam o Brasil como nova moradia. É oportuno ressaltar que apesar de os países da América do Sul como Argentina, Uruguai e Chile não enfrentarem conflitos étnicos políticos e nem situação que propiciem o êxodo de pessoas por questões relacionadas à vulnerabilidade (de forma geral), a amostra contou com a participação de pessoas com tais origens, optou-se por manter tais sujeitos na amostra tendo em vista que, o contexto de identificação com um novo território e língua podem apresentar dificuldades (maiores ou menores, mas mesmo assim dificuldades) na adaptação com o novo contexto.

Com relação às características sociodemográficas, destaca-se o fato de que a maioria dos participantes eram do sexo feminino. Sobre essa questão Hümmelgen e 
Corrêa (2018) chamam a atenção ao fato de que no caso das mulheres, as dificuldades de adaptação podem ser maiores devido à dupla jornada de trabalho feminina e às complicações decorrentes da questão da maternidade. Além disso, as autoras destacam que o ambiente externo da sociedade brasileira, muito hostil, machista e sexista podem criar restrições ainda maiores ao processo de ressocialização (HÜMMELGEN; CORRÊA, 2018), e por consequente barreiras de cunho intrapessoal, interpessoal e ambiental às práticas no lazer. Devendo assim, o Estado responsável por criar estratégias para oferecer condições humanas de sobrevivência digna em solo brasileiro a essas mulheres.

Outra questão a ser levantada é o pouco tempo em que residem em Florianópolis, onde muitos não falam a língua portuguesa fluentemente, problemas com instabilidade e insegurança de sua parte em relação ao acolhimento de si ao contexto atual, também podem ser variáveis que ajudam a explicar as diferenças encontradas (RAMOS, 2009; RAMOS, 2012; REDIN; MINCHOLA, 2013; CAVALCANTI; OLIVEIRA; TONHATI, 2015; GRANADA et al., 2017).

Ainda sobre o perfil da amostra, chama a atenção o fato de que a maioria dos participantes possuíam escolaridade com nível superior, e apesar disso, quase a metade ainda não possuía algum tipo de ocupação. Já os que estavam empregados relataram trabalhar mais de 40 horas semanais. Nesse sentindo, Baeninger (2008) realizou um retrato das condições de vida das famílias de refugiados residentes em São Paulo e Rio de Janeiro, revelando que a maioria desta população estava insatisfeita com as condições de trabalho e os níveis salariais. A autora ainda destaca que apenas $2,8 \%$ estavam contemplados em programas de apoio governamental como o Bolsa família. Esses dados reforçam o grau de vulnerabilidade na qual tais indivíduos se encontram e do preconceito estrutural que a sociedade brasileira ainda possui com esta população. 
Haja vista que, mesmo que não foi questionado a ocupação, acredita-se que muitos, apesar de qualificação são submetidos a subempregos com elevada carga horária e baixa remuneração. Visto que as condições socioeconômicas, na população brasileira, são determinantes para o envolvimento em determinados contextos do lazer (UVINHA et al., 2017; STOPPA; ISAYAMA, 2017; ANDRADE; SCHWARTZ; FELDEN, 2018, ANDRADE et al., 2019)

O presente trabalho também teve como objetivo aprofundar as análises e identificar em que conteúdos culturais do lazer houve diferença entre o país de origem e o contexto atual. Um dos conteúdos culturais do lazer que apresentou tal diferença significativa foi o domínio físico-esportivo. O Guia Brasileiro de Atividade Física para a População Brasileira, recente obra que contou com a participação de diversos pesquisadores da área do movimento humano no Brasil define atividade física como:

[...] um comportamento que envolve os movimentos voluntários do corpo, com gasto de energia acima do nível de repouso, promovendo interações sociais e com o ambiente, podendo acontecer no tempo livre, no deslocamento, no trabalho ou estudo e nas tarefas domésticas (BRASIL, 2021 p. 7).

A atividade física é uma das manifestações mais associadas às práticas contemporâneas no lazer. Consiste em atividades individuais ou coletivas que visam a promoção da saúde e do bem-estar. Nesse contexto, diversas evidências empíricas indicam que o envolvimento com as atividades físicas, vivenciadas no contexto do lazer, podem trazer ressonâncias positivas, tanto no campo da saúde física, quanto à saúde psíquica (RECHTER; SVERDLIK, 2016; JACK; SHE; LIN, 2016). Portanto, a divulgação de programas, equipamentos e espaços de lazer para a prática de atividades físicas podem ser estratégias inteligentes a serem adotadas como mecanismo de ressocialização à população de refugiados. 
Além do conteúdo físico-esportivo, o domínio artístico também apresentou diferença estatística com menor envolvimento no contexto atual. Nesse sentido, no contexto de imigração, autores relacionaram a importância da nova cultura para o desenvolvimento da constituição psíquica do sujeito (FREITAS, 2013; MARTINS, 2013; MORO, 2015; MOUNTIAN; ROSA, 2015). Esta manifestação do lazer diz respeito a tudo que se refere ao imaginário que aguça os sentidos, sob a forma de imagens, emoções e/ou sentimentos relacionados ao estético ao encantamento (MARCELLINO, 2012). Podem ser consideradas como exemplos dessas manifestações, as visitas a museu e exposições de artes, ida ao teatro, cinemas ou espetáculos de dança entre outras manifestações artísticas. No entanto, na sociedade brasileira, poucas pessoas têm acesso ou se identificam essas atividades, sobretudo quando se colocam em ênfase fatores socioeconômicos (DI FANTI; BARBOSA, 2016; ANDRADE; SCHWARTZ; FELDEN, 2018). Além disso, conforme os dados descritivos da amostra notam-se a grande diversidade de culturas e cargas elevadas de trabalho, que associada à falta de suporte social formal e informal, dificultam a adaptação ao envolvimento ao domínio artístico no lazer.

Outro domínio com diferença estatística foi o turístico. Acredita-se que pela situação socioeconômica do público atingido no presente estudo, no qual se deslocam de seu país de origem em busca de uma oportunidade melhor, e que se deparam com situações de preconceito, discriminação e xenofobia, além de postos de trabalho pesados com remuneração baixa, associado à dificuldade de informação e acesso aos serviços públicos (FERREIRA et al., 2010; CAVALCANTI; OLIVEIRA; TONHATI, 2015), a hipótese do nível baixo de envolvimento ao domínio turístico do lazer no contexto atual, por ora já era esperada apriori. No entanto, vale destacar que o conteúdo turístico, não necessariamente diz respeito a exclusivamente a viagens. O conhecer novos espaços, 
incluindo espaços públicos turísticos da cidade onde se reside, também faz parte desta vivência (MARCELLINO, 2012; ANDRADE et al., 2018). Assim, um leque de possibilidades de projetos e políticas emerge, considerando que Florianópolis é um dos principais destinos turísticos do Brasil.

A análise de correlação entre a pontuação da EPL nos dois momentos questionados, revelou índices significativos e positivos. Esses resultados indicam que quanto mais o sujeito realizava atividades no lazer em determinado conteúdo cultural no seu país de origem, maior era também seu envolvimento nos mesmos conteúdos no atual contexto. Isso revela a força de apropriação, do grau de sentidos e significados do lazer e da cultura à pessoa, mantendo assim, mesmo em cenários na qual as adversidades podem dificultar a experimentação, vivas suas raízes e identidades culturais.

\section{Considerações Finais}

Em virtude dos fatos mencionados e dos resultados encontrados na presente pesquisa, identificou-se que o envolvimento dos refugiados residentes em Florianópolis em práticas no lazer foi menor no contexto atual, quando comparado ao contexto de origem. Considerando os conteúdos culturais analisadas a partir da EPL, as principais diferenças foram identificadas foram nos conteúdos artístico, físico-esportivo e turístico. Desta forma, tal população vivencia menos arte, pratica menos atividades físicas e conhece menos novos lugares, atualmente do que na cidade natal. Acredita-se que as condições socioeconômicas e de trabalho podem ser determinantes para as restrições intrapessoais, interpessoais e ambientes ao lazer. Apesar disso, levando em consideração a as correlações identificadas, em todos os domínios do lazer, quanto maior era o envolvimento nas práticas no lazer do indivíduo no país de origem, maior 
também é o seu envolvimento em atividades no lazer no contexto atual, mesmo com o menor envolvimento e com maiores adversidades.

As principais limitações encontradas no presente estudo, em primeiro lugar, foi a escassez de pesquisas empíricas que relacionam o lazer com esta população, especialmente no Brasil. Em segundo lugar, os resultados do presente estudo não são generalizáveis, uma vez que o instrumento da pesquisa foi aplicado somente em uma instituição e com uma restrição amostral bastante significativa. No entanto, acredita-se que tal estudo possa contribuir para um novo olhar para essa população tão carente de oportunidades. Destaca-se a necessidade da implementação de programas e políticas públicas tendo como foco a integração com o contexto atual, seu envolvimento no lazer, visando uma melhor qualidade de vida e dignidade humana.

\section{REFERÊNCIAS}

ANDRADE, R. D. et al. Health and Leisure of Workers of Day and Night Shifts. Ciencia \& trabajo (en línea), Santiago, v. 19, n. 60, p. 143-150, 2017.

. et al. Validade de construto e consistência interna da Escala de Práticas no Lazer (EPL) para adultos. Ciência \& Saúde Coletiva, Rio de Janeiro, v. 23, n. 2, p. 519-528, 2018.

; SCHWARTZ, G.M.; FELDEN, É.P.G. Variáveis Socioeconômicas e o Envolvimento no Lazer: Análise com a Escala de Práticas no Lazer (EPL). Licere, Belo Horizonte, v. 21, n. 1, p. 292-312, 2018. DOI: http://doi.org/10.35699/19813171.2018.1779.

et al.Constraints to leisure-time physical activity among Brazilian workers. Annals of Leisure Research, Waikato,v. 22, p. 202-214, 2019.

BAENINGER, R (coord.). População Refugiada: retrato das condições de vida das famílias em São Paulo e Rio de Janeiro. Campinas: Nepo/ Unicamp, 2008.

BRASIL. Constituição (1988). Constituição da República Federativa do Brasil, 1988. Brasília: Senado Federal, Centro Gráfico, 1988. 292p.

Manual de procedimentos e critérios a aplicar para determinar o Estatuto de Refugiado. Ministério da Justiça. Secretaria Nacional de Justiça, 2018. 
Resolução n. 466, de 12 de dezembro de 2012. Diário Oficial da República

Federativa do Brasil, Brasília, 13 jun. 2013, p. 59.

BRASIL. Guia Brasileiro de Atividade Física para a População Brasileira. Ministério da Saúde. Brasília. 2021.

BRITO, B.T.G. et al. Lazer, atividade física e comportamento sedentário de idosos participantes de um grupo de aconselhamento. Revista Brasileira de Ciência e Movimento, Taguatinga, v. 27, n. 2, p. 97-109, 2019.

CAMARGO, L.O.L. O que é lazer. São Paulo: Brasiliense, 2017.

CAVALCANTI, L.; OLIVEIRA, A.T.; TONHATI, T. A inserção dos imigrantes no mercado de trabalho brasileiro. Brasília: Conselho Nacional de Imigração, 2015.

CONARE. Refúgio em números. Brasília: Ministério da Justiça e da Segurança Pública, 2017. 30 p. Relatório.

DI FANTI, M.G.C.; BARBOSA, V.F. Uma entrevista com Yves Schwartz. Letrônica, Porto Alegre, v. 9, n. esp. (supl.), p. s222-s233, 2016.

FERREIRA, A.P. et al. A experiência migrante: entre deslocamentos e reconstruções. Rio de Janeiro: Garamond, 2010.

FREITAS, M.H. Relações entre religiosidade e saúde mental em imigrantes: implicações para a prática psicológica. Psico-USF, Campinas, v. 18, n. 2, p. 437-444, 2013.

GÁSPARI, J.C.D.; SCHWARTZ, G.M. Adolescência, esporte e qualidade de vida. Motriz, Rio Claro, v. 7, n. 2, p. 107-113, 2001.

GOMES, C.L. Lazer: necessidade humana e dimensão da cultura. Revista Brasileira de Estudos do Lazer, Belo Horizonte, v. 1, n. 1, p. 3-20, 2014.

GRANADA, P et al. Discutir saúde e imigração no contexto atual de intensa mobilidade humana. Interface-Comunicação, Saúde, Educação, Botucatu, v.21, n. 61, p. 285296, 2017.

HOVEY, J.D.; MAGAÑA, C.G. Psychosocial predictors of anxiety among immigrant Mexican migrant farmworkers: Implications for prevention and treatment. Cultural Diversity and Ethnic Minority Psychology, Washington, v. 8, n. 3, p. 274-289, 2002.

HÜMMELGEN, I.; CORRÊA, A. S. Trabalhadoras refugiadas: empregabilidade e condições de trabalho da mulher refugiada no sudeste do Brasil. In Danielle Annoni (org). Direito internacional dos refugiados e o Brasil. Curitiba: Gedai/UFPR, 2018.

JACK, B.M.; SHE, H.C.; LIN, H.S. Effects of self-evaluated value and cognition on leisure science engagement. International Journal of Science Education, Londres, v. 6, n. 4, p. 341-354, 2016.

KAPLAN, D. H.; CHACKO, E. Placing immigrant identities. Journal of cultural geography, [S.1.] v. 32, n. 1, p. 129-138, 2015. 
MARCELLINO, N.C. Estudos do lazer: uma introdução. 5. ed. Campinas: Autores Associados, 2012.

MARTINS, B.L. Migração involuntária como fator de risco à saúde mental. Revista Interdisciplinar da Mobilidade Humana, Brasília, v. 21, n. 40, p. 151-162, 2013.

MEIRA, C. E. V.; ANDRADE, R. D. Atividade física no lazer, capacidade aeróbia percebida e bem-estar subjetivo de acadêmicos de educação física em diferentes fases do curso. Caderno de educação física (Unioeste. Impresso), Marechal Cândido Rondon, v. 19, n. 1, p. 13-21, 2019.

MORO, M.R. Psicoterapia transcultural da migração. Psicologia USP, São Paulo, v. 26, n. 2, p. 186-192, 2015.

MOUNTIAN, L.; ROSA, M.D. O outro: análise crítica de discursos sobre imigração e gênero. Psicologia USP, São Paulo, v. 26, n. 2, p. 152-160, 2015.

MURAD, S; VERSEY, H. Shellae. Barriers to leisure-time social participation and community integration among Syrian and Iraqi refugees. Leisure Studies,Abingdon, v. 40, n. 3, p. 1-14, 2020.

NAHAS, M.V. et al. Lazer ativo: um programa de promoção de estilos de vida ativos e saudáveis para o trabalhador da indústria. Revista Brasileira de Atividade Física e Saúde, Pelotas, v. 15, n. 4, p. 260-264, 2010.

NIKOLOVA, M.; GRAHAM, C. In transit: The well-being of migrants from transition and post-transition countries. Journal of Economic Behavior \& Organization, Amsterdam, v. 112, p. 164-186, 2015.

ONU - Organização das Nações Unidas. Convenção das Nações Unidas relativa ao Estatuto dos Refugiados. Genebra, 1951.

PRILLELTENSKY, I. Migrant Well-Being is a Multilevel, Dynamic, Value Dependent Phenomenon. American Journal of Community Psychology, [S.1], v. 42, n. 3-4, p. 359-364, 2008.

RAMOS, M. P. R. Comunicação em saúde e interculturalidade: perspectivas teóricas, metodológicas e práticas. RECIIS - Revista Eletrônica de Comunicação Informação \& Saúde, Rio de Janeiro, v. 6, n. 4, p. 1-19, 2012.

RAMOS, N. Saúde, migração e interculturalidade. Mudança - Psicologia e Saúde, São Bernardo do Campo, v. 17, n. 1, p. 1-11, 2009.

RECHTER, E.; SVERDLIK, N. Adolescents and teachers outlook on leisure activities: Personal values as a unifying framework. Personality and Individual Differences, Malden, v. 99, p. 358-367, 2016.

REDIN, G.; MINCHOLA, L.A.B. Proteção dos refugiados na declaração de Cartagena de 1984: Uma análise a partir do caso dos Haitianos no Brasil. Revista de Estudos Internacionais, João Pessoa, v. 4, n. 1, p. 30-45, 2013. 
SLONIM-NEVO, V. et al. Ethnicity versus migration: Two hypotheses about the psychosocial adjustment of immigrant adolescents. The International Journal of Social Psychiatry, Londres, v. 52, n. 1, p. 41-53, 2006.

STOPPA, E. A.; ISAYAMA, H. F. Lazer no Brasil: Representações e Concretizações das Vivências Cotidiana. Campinas: Autores Associados, 2017.

UVINHA, R. R., et al. Leisure practices in Brazil: a national survey on education, income, and social class. World Leisure Journal, [S.1.] v. 59, p. 1-12, 2017.

\section{Endereço dos Autores:}

Rubian Diego Andrade

Endereço Eletrônico: rubiandiego@gmail.com

Caio Hercilio Martins

Endereço Eletrônico: caioomartinss@gmail.com 